\title{
A new species of Gammarus Fabricius, 1775 (Crustacea: Amphipoda: Gammaridae) from extreme high-altitude Lake Tong Tso, Qinghai-Tibetan Plateau
}

\author{
Luiz Felipe Andrade'; Marcos Tavares² \& André Resende de Senna ${ }^{3}$
}

1 Universidade Federal de Pernambuco (UFPE), Centro de Tecnologia e Geociências (CTG), Departamento de Oceanografia,
Museu de Oceanografia “Prof. Petrônio Alves Coelho". Recife, PE, Brasil.
ORCID: http://orcid.org/0000-0002-4868-737X. E-mail: Izflp.andrade@hotmail.com (corresponding author)
2 Universidade de São Paulo (USP), Museu de Zoologia (MZUSP). São Paulo, SP, Brasil.
ORCID: http://orcid.org/0000-0002-7186-5787. E-mail: mdst@usp.br
3 Universidade do Estado do Rio de Janeiro (UERJ), Centro de Educação e Humanidades (CEH), Faculdade de Formação de Professores (FFP),
Departamento de Ciências. São Gonçalo, RJ, Brasil. ORCID: http://orcid.org/0000-0003-0976-849X. E-mail: senna.carcinologia@gmail.com

\begin{abstract}
A new species of the genus Gammarus Fabricius, 1775 is described from Lake Tong Tso, an extreme high-altitude lake in the Qinghai-Tibetan Plateau. Gammarus pontual sp. nov. is considered part of the Gammarus lacustris G.0. Sars, 1863 group, which is characterized by having the inner ramus of uropod 3 longer than half the length of the outer ramus, and by having both rami covered with plumose setae. The new species stands apart from their congeners, mainly, by the following combination of characters: head with cephalic lateral lobe truncated; gnathopods 1-2 propodus weakly armed, with 1 stout seta defining palm; palm longer than posterior margin of propodus, with 1 main stout seta medially; pereopods 5-7 basis slender, posterior margin crenulate; epimeral plate 1 posterior margin produced into a short spine, facial ridge present; epimeral plates 2-3 posteroventral corner sharply pointed; uropod 3 rami covered with plumose setae, inner ramus about $80 \%$ the length of the outer ramus; telson apex with 2 stout setae on each side.
\end{abstract}

Keywords. Senticaudata; Taxonomy; Tibet; High-altitude Lake.

\section{INTRODUCTION}

Gammaridae Leach, 1814, is a monophyletic family whose members are often found inhabiting springs, rivers, streams, lakes, lagoons, and marine littoral zones (Hou \& Sket, 2015). It consists of 42 genera, of which Gammarus Fabricius, 1775 , is the most speciose and diverse. The genus is widely spread in the Holoarctic realm, consisting of 268 species whose distribution centered in Europe, but ranges as far as North America to the west and China to the east (Väinölä et al., 2008; Horton et al., 2021 onwards).

Currently, 15 Gammarus species in four species groups are known from the Tibetan Plateau, of which 14 are considered endemic (Hou \& Li, 2018). In this paper, we describe a new species of Gammarus of the G. lacustris species group from the Qinghai-Tibetan Plateau.

\section{MATERIAL AND METHODS}

Five specimens were manually collected from shallow depths $(10$ to $20 \mathrm{~cm}$ ) in the extreme high-altitude saltwater lake Tong Tso, QinghaiTibetan Plateau, 4,399 meters above sea level. All specimens are preserved in $70 \%$ ethanol and deposited at the Museu de Zoologia, Universidade de São Paulo (MZUSP).

For the taxonomic study, the mouthparts and appendages were dissected and mounted in glycerin gel slides. The drawings were made under an optical microscope with camera lucida, Leica DM 5000 B, and digitized with CorelDRAW 2018. The setal/spine classification adopted in this paper follows Garm \& Watling (2013) and the nomenclature of gnathopod palms is based on Poore \& Lowry (1997). Measurements refer to the total body length. 


\section{RESULTS}

Taxonomic analysis

Order Amphipoda Latreille, 1816

Suborder Senticaudata Lowry \& Myers, 2013

Family Gammaridae Leach, 1814

Genus Gammarus Fabricius, 1775

Type species: Gammarus pulex (Linnaeus, 1758).

\section{Gammarus pontual sp. nov.}

(Figs. 1-8)

Material examined: Holotype, male, $41.1 \mathrm{~mm}$, in ethanol 70\%, habitus illustrated, Lake Tong Tso, approximately $32^{\circ} 10^{\prime} 0^{\prime \prime} \mathrm{N}, 84^{\circ} 42^{\prime} 0^{\prime \prime} \mathrm{E}$, Qinghai-Tibetan Plateau, 10-20 cm depth, coll. F. Pontual, August-September, 2000 (MZUSP 40976).

Paratypes: 1 male, $27.0 \mathrm{~mm}$, dissected and illustrated, same sampling data as holotype (MZUSP 40977); 3 males, $16.6 \mathrm{~mm}, 17.8 \mathrm{~mm}$, and $21.4 \mathrm{~mm}$, in ethanol 70\%, same sampling data as holotype (MZUSP 40130).

Diagnosis: Head with deep antennal sinus. Maxilla 2 inner plate with a very dense facial oblique row of setae. Gnathopod 1 propodus weakly armed, lateral margin with 1 stout seta defining palm, palm longer than posterior margin of propodus, with a truncated projection bearing 1 stout seta medially. Gnathopod 2 propodus weakly armed, palm lateral margin with a proximal large subrounded projection bearing 1 main stout seta. Pereopods 5-7 basis slender, posterior margin crenulate. Epimeral plate 1 posterior margin produced into a short spine, facial ridge present. Epimeral plates 2-3 posteroventral corner sharply pointed. Uropod 3 rami covered with plumose setae. Telson apex with 2 stout setae on each side.

Description: Based on male holotype (MZUSP 40976) and male paratype (MZUSP 40977). Habitus as in Fig. $1 \mathrm{~A}$. Head (Fig. 2A), cephalic lateral lobe truncated, antennal sinus deep, eyes small and ovate. Antenna 1 (Fig. 2B) about 1.2 times longer than antenna 2, peduncular articles 1-3 with length ratio of 1.0: 0.8: 0.4, weakly setose; accessory flagellum 3-articulate; main flagellum 23-articulate, calceoli absent. Antenna 2 (Fig. 2C) peduncular articles 3-5 with length ratio of 1.0: 2.4: 2.5; article 2 short, gland cone straight, almost reaching apex of third article; article 3 with main lateral ridge bearing 7 setae and small hump with 3 setae; article 4 ventral margin with 6 short brush setae proximally and 8 clusters of short to long setae laterally; article 5 ventral margin with 1 long seta distally, 9 clusters of short to long setae laterally; flagellum 14-articulate, calceoli absent. Upper lip (Fig. 2D) ventral margin rounded, setulose. Lower lip (Fig. 2E) outer lobes large, setulose, inner lobes indistinct. Left mandible (Fig. 2F) incisor with 5 spines; lacinia mobilis with 4 spines; accessory setal row with 10 plumose setae; molar triturative, with 1 plumose seta; palp articles 1-3 with length ratio of 1.0: 2.5: 2.0; article 2 with 18 setae; article 3 facial margin with 3 clusters of setae, mesial margin with 32 weakly serrulated setae and 7 slender setae apically. Right mandible (Fig. 2G) incisor with 4 spines; lacinia mobilis apically trifid, facially multicuspidate; accessory setal row with 8 plumose setae; molar triturative, with 1 long plumose seta; palp articles 1-3 length ratio of 1.0: 2.4: 1.9; article 2 with 16 setae; article 3 facial margin with 3 clusters of setae, mesial margin with 28 pectinate setae and 9 slender setae apically. Maxilla 1 (Fig. 3A) inner plate with 30 plumose setae, facial and apicolateral margins covered with setules; outer plate mesial margin with row of setules, apically with 9 serrate stout setae, facially with oblique row of setules, ending in setulose field; left palp 2-articulate, bearing 9 setae apically, 6 subapically; right palp (Fig. 3B) apical margin with 6 short stout and 2 slender setae. Maxilla 2 (Fig. 3C) inner plate about 0.9 times length of outer plate, strongly setose, with facial oblique row of 53 slender setae, laterally and facially covered with setules; outer plate setose apically, lateral and facial margins covered with setules. Maxilliped (Fig. 3D) inner plate with 3 apical and 1 subapical stout setae, mesial and apical margins covered with plumose setae, facial margin with oblique row of 7 multicuspidate setae; outer plate mesial margin with 15 stout setae, apical margin with 3 serrate and 5 plumose setae, lateral margin covered with setules; palp 4-articulate, article 1 mesial margin with 5 setae, article 2 mesial margin setose, apicolateral corner with row of 6 setae, article 3 with oblique facial row of 8 pectinate setae, lateral margin with 3 clusters of setae, apicolateral corner produced into a hump, article 4 about half the length of article 3, with 6 short setae distally, bearing one medium nail.

Gnathopod 1 (lateral view) (Fig. 4A) coxa subrectangular, anteroventral and posteroventral corners with small spine bearing 1 short seta each; basis about 2.5 times longer than wide, margins with short to long setae, posterior margin with 4 serrate setae and 1 pectinate setae distally; ischium posterior margin with 8 setae distally; merus posterior margin weakly setose; carpus about 0.7 times length of propodus, anterior margin with 4 cluster of setae, posterior margin setose with pectinate setae; propodus about 1.3 times longer than wide, anterior margin with 8 setae distally, posterior margin with 3 clusters of setae, 1 stout seta defining palm; palm 1.4 times longer than posterior margin of propodus, proximally with truncate projection bearing 1 stout seta and two pairs of stout setae medially and distally; dactylus shorter than palm, outer margin with 1 seta, nail present. Gnathopod 1 (mesial view) (Fig. 4B) ischium posterior margin with row of 11 setae extending to facial margin; merus facial margin with subdistal ridge bearing 17 setae; merus anterior margin with 3 clusters of setae, posterior margin setose with pectinate setae, facial margin with 2 rows of 6 and 15 setae medially and distally, respectively; propodus anterior margin with tuft of setae distally, posterior margin weakly setose, 1 stout seta defining palm, facial margin with clusters of slender se- 
tae and 2 clusters bearing 3 stout and 1 slender setae, plus 1 stout and two slender setae; palm covered with short setae, distally crenulate towards palmar corner. Gnathopod 2 (lateral view) (Fig. 5A) coxa subrectangular, tapering distally, anteroventral and posteroventral corners with small spine bearing 1 short seta each; basis about 2.7 times longer than wide, margins with short to long setae, posterior margin with 5 distal serrate setae decreasing in length; ischium posterior margin with 5 setae distally; merus facial margin with row of 20 setae distally; carpus about 0.7 times length of propodus, anterior margin with 3 clusters of setae, posterior margin setose with pectinate setae; propodus about 1.5 times longer than wide, anterior margin with 11 setae distally, posterior margin moderately setose, with 1 stout seta defining palm; palm 0.6 times length of posterior margin of propodus, with large subrounded projection bearing 1 main stout seta medially, distally with another subrounded projection and two stout setae decreasing in length; dactylus slightly longer than palm, outer margin with 1 seta, nail present. Gnathopod 2 (mesial view) (Fig. 5B) ischium posterior margin with row of 11 setae extend-

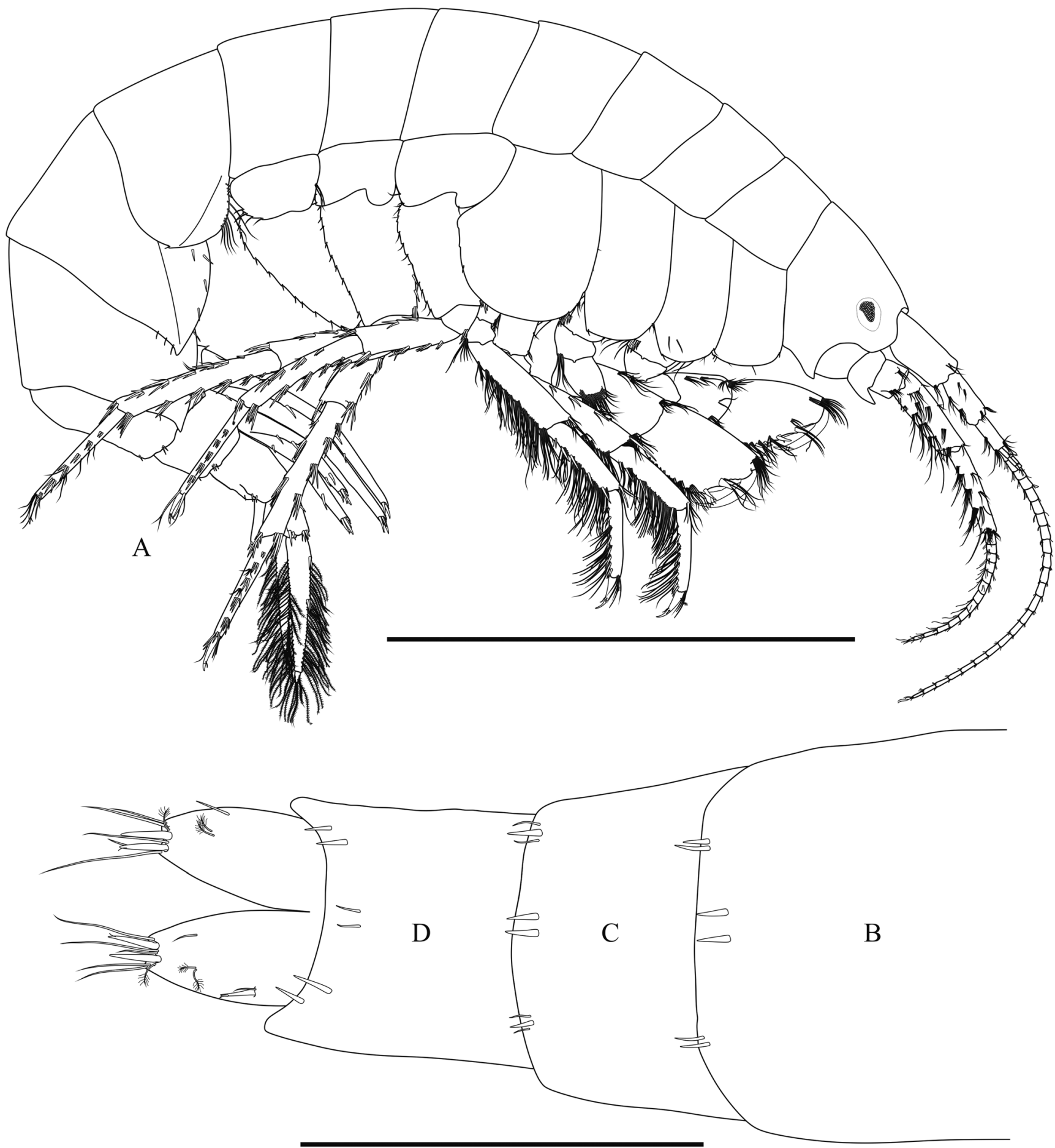

Figure 1. Gammarus pontual sp. nov., male holotype (MZUSP 40976): (A) Habitus, lateral view; (B-D) Urosomites 1-3, dorsal view, respectively. Scale bars: 10.0 mm for $A ; 2.0 \mathrm{~mm}$ for B-D. 
ing to facial margin; merus facial margin with 2 rows of long setae; carpus anterior and facial margins with cluster of setae, posterior margin setose with pectinate setae; propodus posterior margin covered with pectinate setae, facial margins with many clusters of slender setae, one with 3 stout setae; palm minutely crenulate, covered with short setae. Pereopod 3 (Fig. 6A) coxa anteroventral corner with 1 short seta, posteroventral corner with small

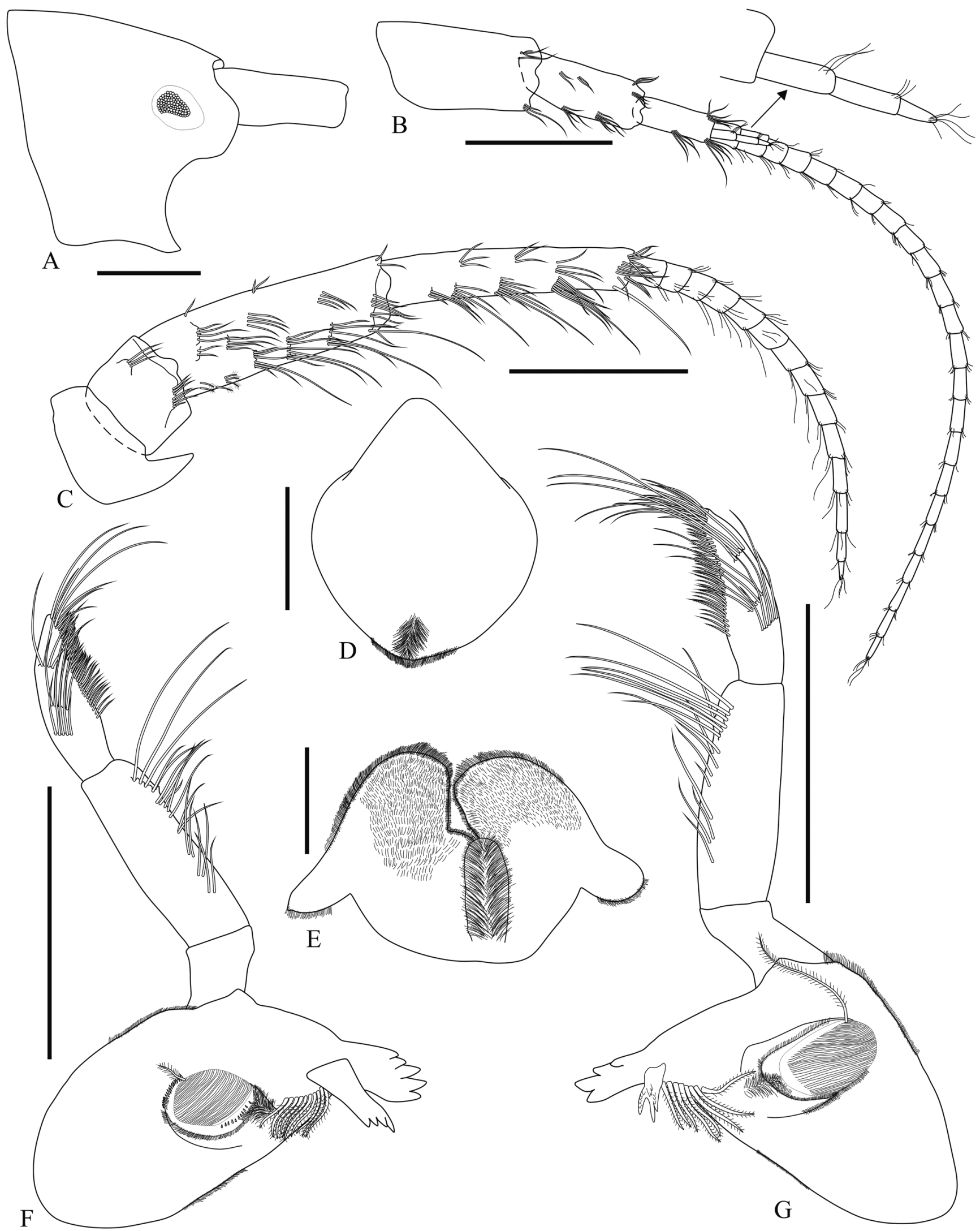

Figure 2. Gammarus pontual sp. nov., male paratype (MZUSP 40977): (A) Head, lateral view; (B) Right antenna 1, lateral view; (C) Right antenna 2, lateral view; (D) Upper lip, dorsal view; (E) Lower lip, dorsal view; (F) Left mandible, mesial view; (G) Right mandible, mesial view. Scale bars: $1.0 \mathrm{~mm}$. 
spine bearing 1 short seta; basis about 3.7 times longer than wide, margins moderately setose; ischium posterior margin with 5 setae distally; merus, carpus, propodus and dactylus with length ratio of 1.0: 0.6: 0.6: 0.2; merus anterior margin with 4 clusters of setae with 1 stout seta each, posterior margin setose, facial margin with 5 clusters of

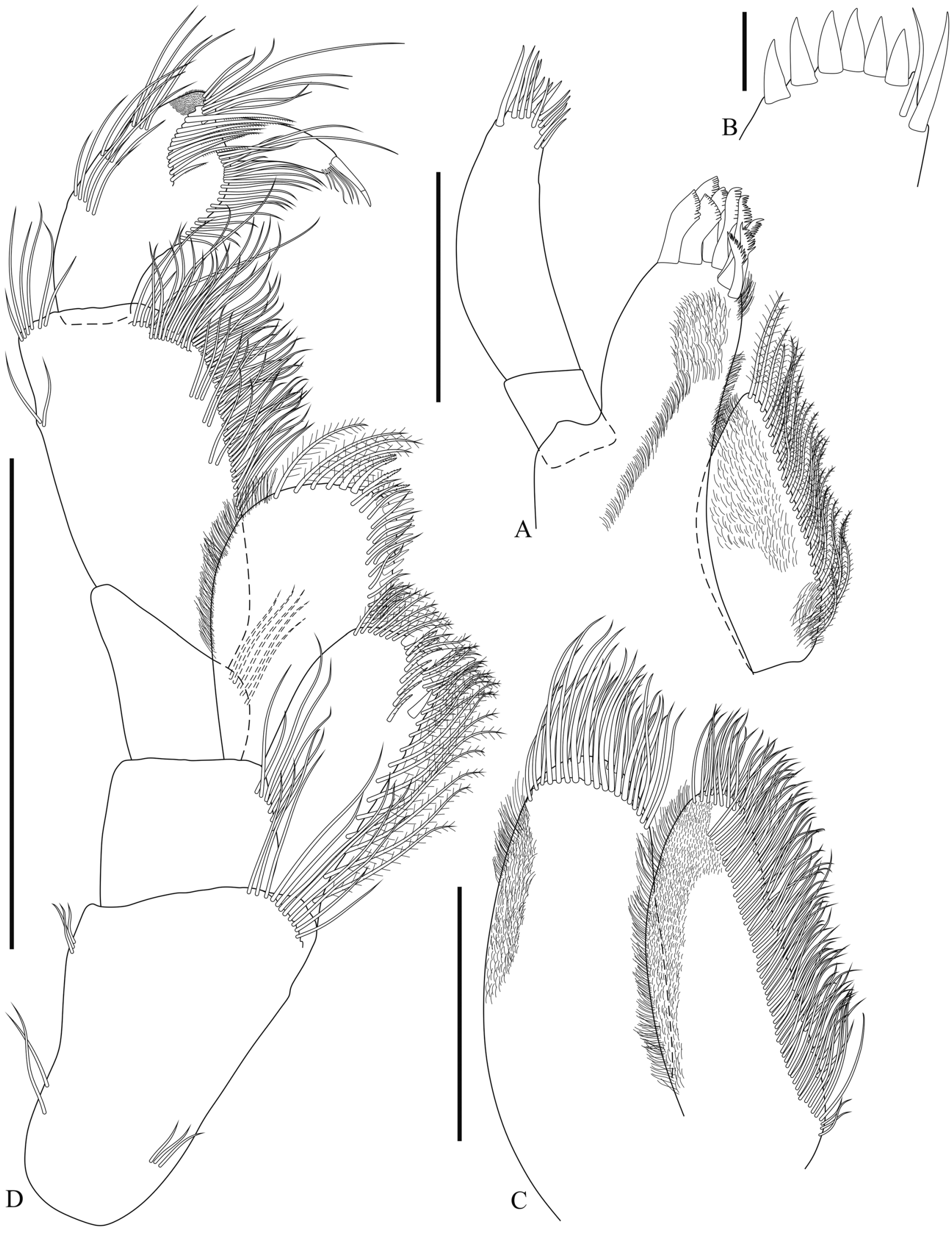

Figure 3. Gammarus pontual sp. nov., male paratype (MZUSP 40977): (A) Left maxilla 1, dorsal view; (B) Detail of the right palp of maxilla 1, dorsal view; (C) Left maxilla 2, dorsal view; (D) Left maxilliped, dorsal view. Scale bars: $0.1 \mathrm{~mm}$ for $B ; 1.0 \mathrm{~mm}$ for $D ; 0.5 \mathrm{~mm}$ for the remaining. 
setae; carpus anterior margin with 1 stout and 5 slender setae distally, posterior margin setose, with 4 stout setae; propodus anterior margin with 3 setae distally, posterior margin moderately setose, with 7 stout setae; dactylus anterior margin with 1 short plumose seta proximally, facial and posterior margins with 1 seta each, nail present.

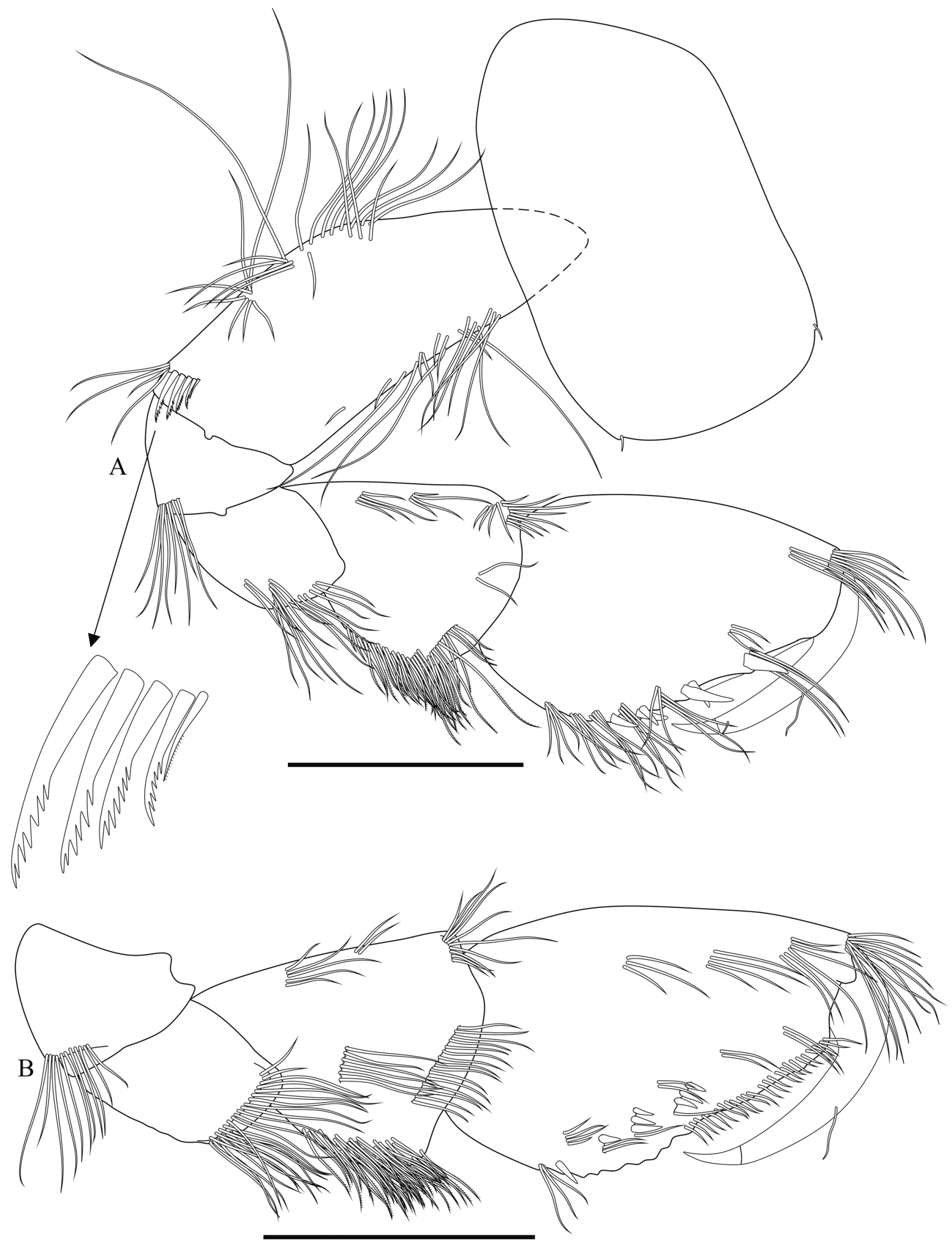

Figure 4. Gammarus pontual sp. nov., male paratype (MZUSP 40977): (A) Right gnathopod 1, lateral view; (B) Left gnathopod 1, mesial view. Scale bars: 1.0 mm. 
Pereopod 4 (Fig. 6B) coxa narrow, about 1.2 times longer than wide, excavate posterodorsally, anteroventral corner with 2 short setae; basis about 3.6 times longer than wide, margins moderately setose; ischium posterior margin with 7 setae distally; merus, carpus, propodus and dactylus with length ratio of 1.0: 0.7: 0.7: 0.2; merus anterior margin with 1 stout and 4 slender setae distal- ly, posterior margin setose; carpus anterior margin with 1 stout and 3 slender setae, posterior margin setose, with 5 stout setae; propodus anterior margin with 4 setae distally, posterior margin moderately setose, with 9 stout setae; dactylus anterior margin with 1 short plumose seta proximally, facial and posterior margins with 1 seta each, nail present. Pereopod 5 (Fig. 6C) coxa bilobate, ante-
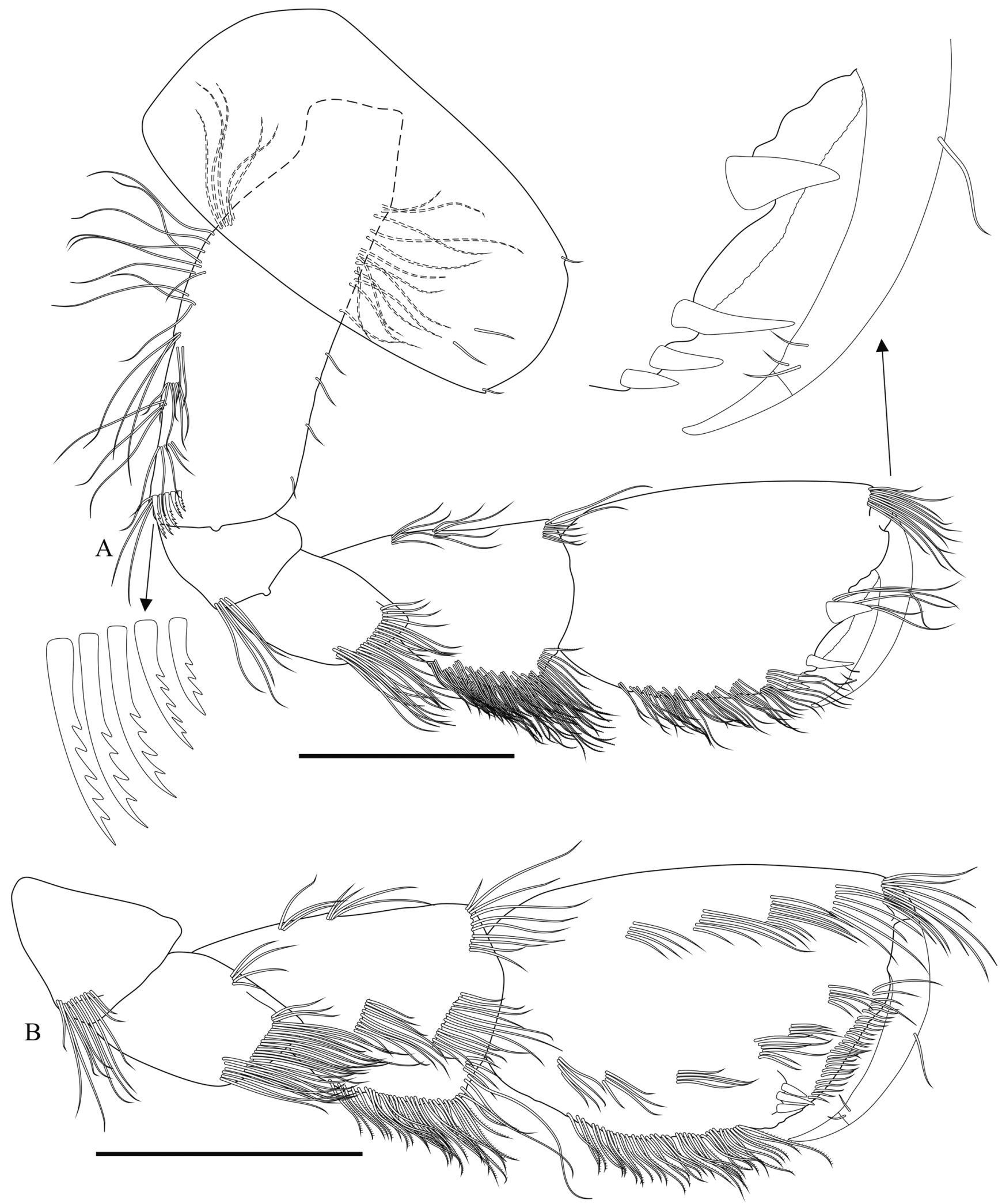

Figure 5. Gammarus pontual sp. nov., male paratype (MZUSP 40977): (A) Right gnathopod 2, lateral view; (B) Left gnathopod 2, mesial view. Scale bars: $1.0 \mathrm{~mm}$. 
rior lobe with 1 seta, posterior lobe with 2 setae; basis about 1.6 times longer than wide, tapering distally, anterior margin with 10 stout setae, posterior margin weakly crenulate, with 10 setae; ischium anterior margin with
1 slender and 2 stout setae; merus, carpus, propodus and dactylus with length ratio of 1.0: 1.2: 1.0: 0.3; merus anterior and posterior margins with 4 and 3 clusters of stout setae, respectively; carpus anterior and posterior

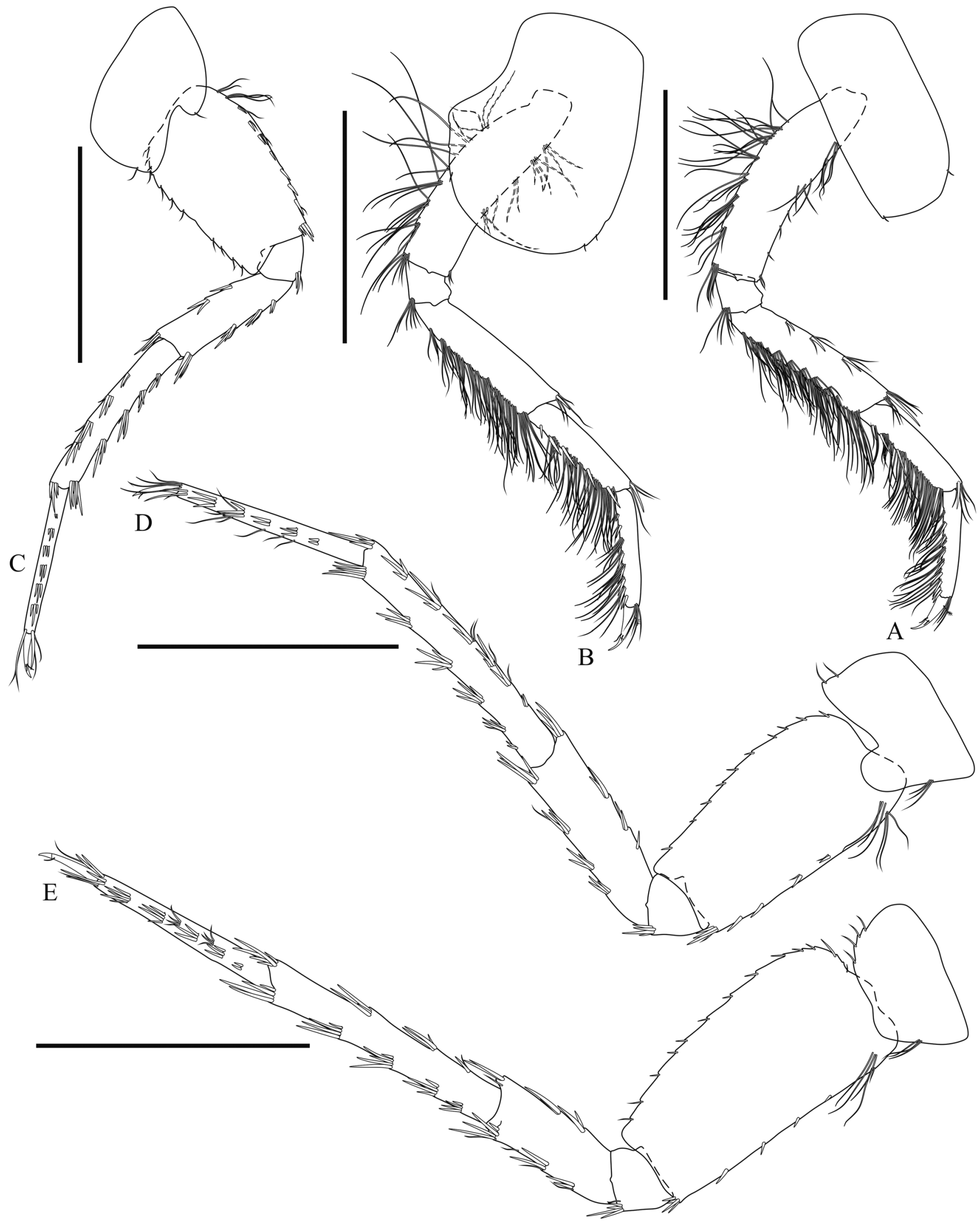

Figure 6. Gammarus pontual sp. nov., male paratype (MZUSP 40977): (A) Right pereopod 3, lateral view; (B) Right pereopod 4, lateral view; (C) Right pereopod 5, lateral view; (D) Right pereopod 6, lateral view; (E) Right pereopod 7, lateral view. Scale bars: $1.0 \mathrm{~mm}$. 
margins with 5 clusters of stout setae each; propodus with 6 clusters of stout setae; dactylus facial and anterior margins with 1 seta each, nail present. Pereopod 6 (Fig. 6D) coxa bilobate, anterior margin with 3 setae, posterior margin with 2 setae; basis about 1.8 times longer than wide, tapering distally, anterior margin with 7 stout setae, posterior margin crenulate, with 10 short setae; ischium anterior margin with 4 stout setae distally; merus, carpus, propodus and dactylus with length ratio of 1.0: 1.3: 0.9: 0.2; merus anterior and posterior margins
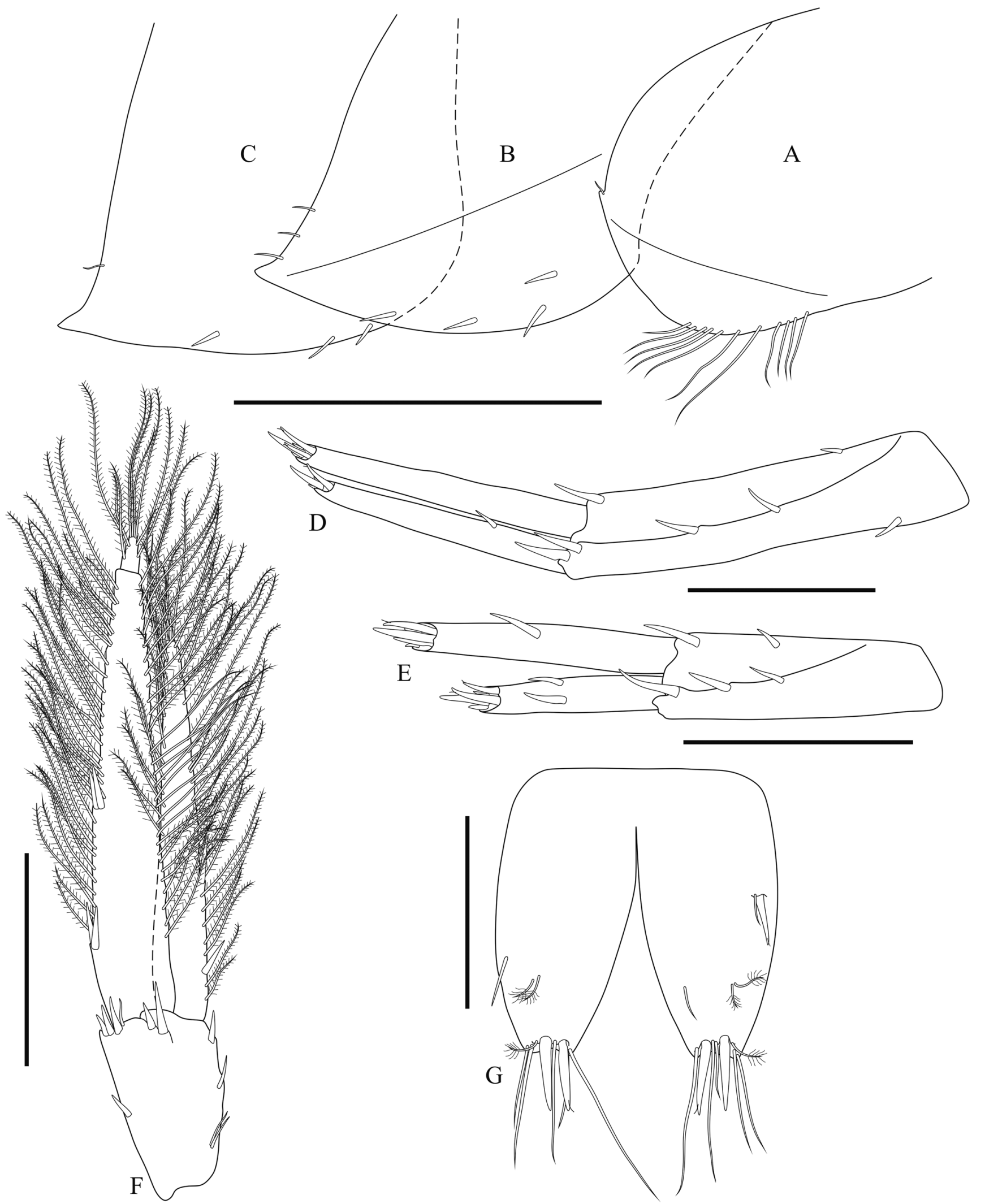

Figure 7. Gammarus pontual sp. nov., male holotype (MZUSP 40976): (A-C) Epimeral plates 1-3, lateral view, respectively. Male paratype (MZUSP 40977): (D-F) Uropods 1-3, lateral view, respectively; (G) Telson, dorsal view. Scale bars: $0.5 \mathrm{~mm}$ for G; $2.0 \mathrm{~mm}$ for A-C; $1.0 \mathrm{~mm}$ for the remaining. 
with 4 and 3 clusters of stout setae, respectively; carpus anterior and posterior margins with 6 and 7 clusters of stout setae, respectively; propodus with 5 clusters of stout setae; dactylus anterior margin with 1 seta each, nail present. Pereopod 7 (Fig. 6E) coxa anterior margin with tuft of 3 setae, posterior margin weakly crenulate, with 4 setae; basis about 1.9 times longer than wide, tapering distally, anterior margin with 8 stout setae, posterior margin crenulate, with 13 setae; ischium anterior margin with 4 stout setae; merus, carpus, propodus and dactylus with length ratio of 1.0: 1.6: 1.2: 0.3 ; merus anterior and posterior margins with 3 clusters of stout se-

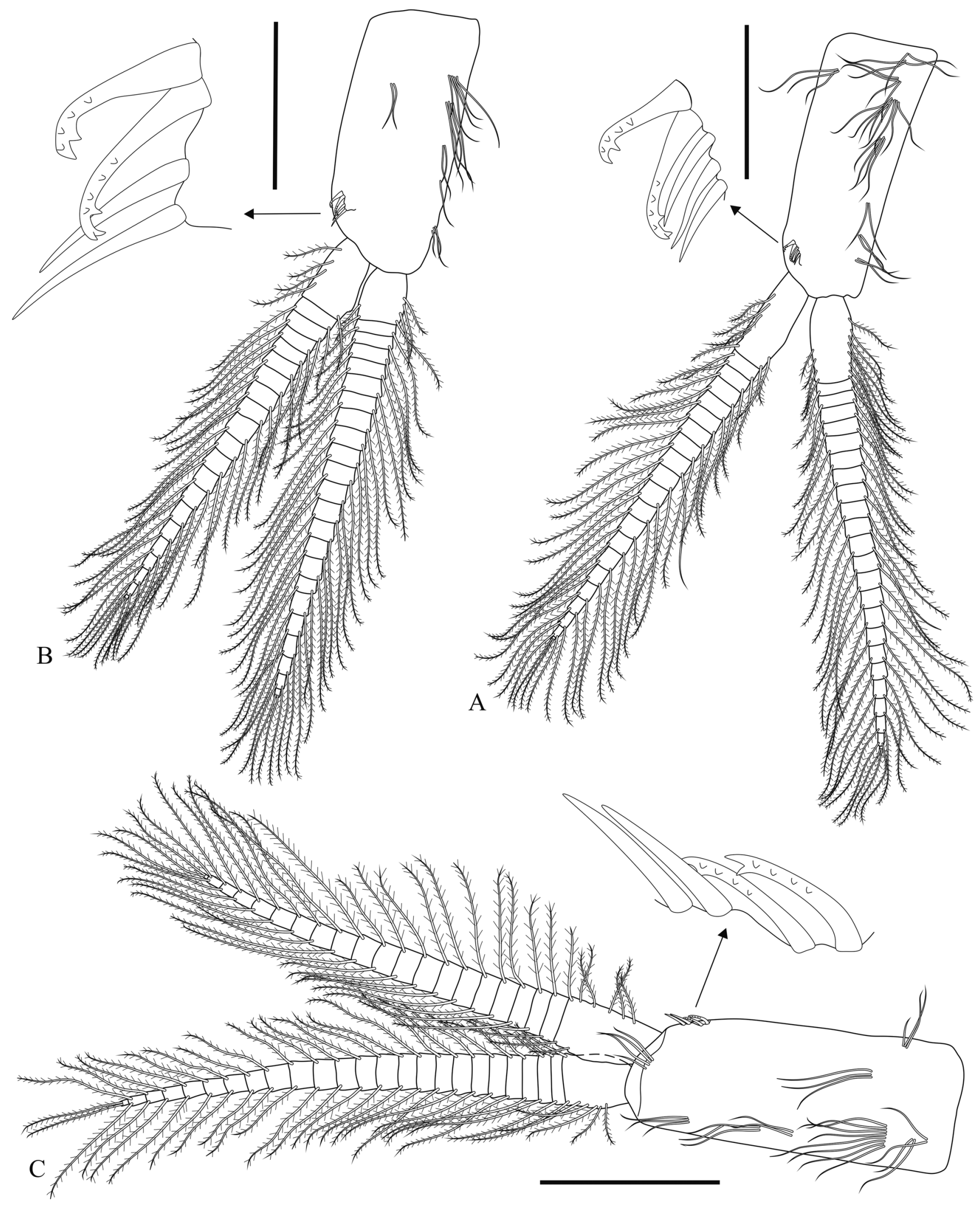

Figure 8. Gammarus pontual sp. nov., male paratype (MZUSP 40977): (A-C) Pleopods 1-3, dorsal view, respectively. Scale bars: $1.0 \mathrm{~mm}$. 
tae each; carpus anterior and posterior margins with 5 and 4 clusters of stout setae, respectively; propodus with 6 clusters of stout setae and 2 of slender setae; dactylus anterior margin with 1 short seta, nail present.

Epimeral plate 1 (Fig. 7A) anterior margin with 11 setae extending to anteroventral corner, facial ridge present, posteroventral corner with short spine bearing 1 short seta, posterior margin rounded. Epimeral plate 2 (Fig. 7B) anterior margin weakly concave, facial ridge present, with 1 facial stout seta, ventral margin with 3 submarginal stout setae, posteroventral corner sharply pointed, posterior margin with 3 setae. Epimeral plate 3 (Fig. 7C) anterior margin weakly concave, anteroventral corner with 2 stout setae, ventral margin with 1 submarginal stout seta, posteroventral corner sharply pointed, posterior margin with 1 seta. Pleopod 1 (Fig. 8A) peduncle with sparse clusters of setae, innerdistal margin with 2 retinacula and 3 slender setae; rami subequal, covered with plumose setae, with 21-24 articles. Pleopod 2 (Fig. 8B) peduncle with sparse submarginal clusters of setae, innerdistal margin with 2 retinacula and 2 slender setae; rami subequal, covered with plumose setae, with 21-23 articles. Pleopod 3 (Fig. 8C) peduncle with sparse clusters of setae, innerdistal margin with 2 retinacula and 2 slender setae; rami subequal, covered with plumose setae, with 21-25 articles. Urosomite 1 (Fig. 1B) dorsally with 2-2-2 stout setae. Urosomite 2 (Fig. 1C) dorsally with 1-2-1 stout setae accompanied by slender setae. Urosomite 3 (Fig. 1D) dorsal margin with 2-0-2 stout setae, bearing 2 slender setae in the middle. Uropod 1 (Fig. 7D) peduncle about 4.4 times longer than wide, with 1 stout basofacial seta, dorsomesial margin with 2 stout setae, dorsolateral margin with 4 stout setae; inner ramus slightly longer than outer, about 0.7 times the length of peduncle, dorsal margin naked, apically with 5 stout setae; outer ramus about 0.6 times the length of peduncle, dorsal margin with 1 stout seta, apically with 4 stout setae. Uropod 2 (Fig. 7E) peduncle about 3.3 times longer than wide, dorsomesial margin with 2 stout setae, dorsolateral margin with 3 stout setae; inner ramus about 1.4 times longer than outer and slightly shorter than peduncle, dorsal margin with 1 stout seta, apically with 5 stout setae; outer ramus dorsal margin with 2 stout setae, apically with 5 stout setae. Uropod 3 (Fig. 7F) peduncle about 1.5 times longer than wide, distolaterally with 1 slender and 5 stout setae, distomesially with 1 stout seta; outer ramus about 1.2 times longer than inner, covered with long plumose setae, ventral margin with 2 pairs of 2 stout setae, article 2 short, apically with 4 long plumose setae; inner ramus covered with plumose setae. Telson (Fig. 7G) slightly longer than wide, about $80 \%$ cleft, exceeding the peduncle of uropod 3, apically with 2 stout, 1 brush and 5 slender setae, dorsally with 1 slender and 2 brush setae on each side, dorsolaterally with 1 stout and 1 short slender setae on one side only.

Etymology: This species is named after conservation biologist Francisco Pontual, in recognition for his efforts directed towards habitat protection. The specific epithet, pontual, is to be used as a name in apposition.

Type locality: Lake Tong Tso, Qinghai-Tibetan Plateau, $32^{\circ} 10^{\prime} 0^{\prime \prime} \mathrm{N}, 84^{\circ} 42^{\prime} 0^{\prime \prime} \mathrm{E}$.

Remarks: Gammarus pontual sp. nov. is herein assigned to Gammarus, whose diagnostic characters (cf., Zamanpoore et al., 2011) are readily recognized in the new species. They are as follow: head with truncated cephalic lateral lobe and small eyes (Fig. 2A); antenna 1 with developed accessory flagellum (Fig. 2B); antenna 2 without calceoli (Fig. 2C); maxillae 1-2 (Fig. 3A, C, respectively) with mesial margins densely setose; coxa 4 posteriorly excavated (Fig. 6C); gnathopod 2 (Fig. 5A, B) larger than 1; pereopods (Fig. $6 \mathrm{~A}-\mathrm{E}$ ) with stout and slender setae; epimeral plates 2-3 (Fig. 7B, C) posteroventral corner acute; rami of uropod 3 (Fig. 7F) densely setose; telson (Fig. 7G) cleft, lobes with stout and slender setae apically.

Four species group of Gammarus have been recognized from the Tibetan Plateau (viz. Hou \& Li, 2018): (1) the G. lacustris G.O. Sars, 1863 species group, consisting of five species, defined by the uropod 3 inner ramus longer than half of the length of the outer ramus, and by having both rami covered with plumose setae; (2) the cave-dwelling group, encompassing two eyeless species; (3) the G. sinuolatus Hou \& Li, 2004 species group composed of one species and characterized by the uropod 3 with both rami bearing long simple setae; and (4) G. kangdingensis Hou \& Li, 2018 species group formed by seven species with rami of uropod 3 presenting few simple or plumose setae (Hou \& Li, 2018).

Gammarus pontual sp. nov. clearly belongs to the G. lacustris G.O. Sars, 1863 species group, which consists of five species: G. lacustris; G. lasaensis Barnard \& Dai, 1988; G. hongyuanensis Barnard \& Dai, 1988; G. frigidus Hou \& Li, 2004; and G. jaspidus Hou \& Li, 2004. The new species additionally resembles the species in the $G$. lacustris species group by presenting the following characters: truncated cephalic lateral lobe; weakly setose coxae 1-7; pyriform gnathopod 1 propodus; subrectangular gnathopod 2 propodus. However, Gammarus pontual sp. nov. differs from the above congeners as follows: from G. lacustris in having (character states in G. lacustris within round brackets) small eyes (Fig. 2A) (vs medium size eyes); maxilla 2 (Fig. $3 \mathrm{C}$ ) strongly setose (vs moderately setose); short gnathopod 1 (Fig. 4A, B) carpus, about 1.3 times longer than wide (vs 1.6 times longer than wide), propodus lateral margin without facial stout setae (vs facial stout setae formula 3-2-1-1); palm defined by 1 stout seta ( $v$ s palm defined by 2 stout setae); gnathopod 2 (Fig. 5A, B) mesial margin with facial cluster of 3 stout setae near palmar corner (vs mesial side with only 1 stout seta); pereopods 5-7 (Fig. 6C-E) with basis slender ( $v s$ basis robust); posterior margin of epimeral plate 1 (Fig. 7A) produced into a short spine (vs posterior margin not produced); posteroventral spine of the epimeral plates 2-3 (Fig. 7B, C) moderately projected and rather blunt (vs strongly projected and sharp); urosomites 1-3 (Fig. 1B-D) dorsal stout setae formula: 2-2-2, 1-2-1, and 
2-0-2 (vs formula 1-2-1, 1-2-1, and 1-0-1, respectively); telson (Fig. 7G) dorsolateral margin with 1 stout seta (vs stout setae absent).

It differs from $G$. lasaensis in having (character states in G. lasaensis within round brackets): small eyes (Fig. 2A) (vs large size eyes); antenna 2 (Fig. 2C) without calceoli (vs calceoli present), gland cone straight (vs curved upwards); gnathopod 1 (Fig. 4A, B) propodus mesial margin without facial stout setae ( $v$ s facial stout setae formula 3-2-1), palm defined by 1 stout seta and weakly armed (vs defined by 2 stout setae and strongly armed); gnathopod 2 (Fig. 5A, B) palm lateral margin with only 1 stout seta medially (vs 3 stout setae); epimeral plate 1 (Fig. 7A) posterior margin glabrous (vs posterior margin provided with 3 setae); epimeral plates 2-3 (Fig. 7B, C) posteroventral corner sharply pointed in a moderate length (vs stronger length and more acute corner); urosomites 1-3 (Fig. 1B-D) with dorsal stout setae formula: 2-2-2, 1-2-1, and 2-0-2 (vs formula 3-2-3, 3-2-3, and 3-2-3, respectively); length of telson (Fig. 7G) exceeding the peduncle of uropod 3 ( $v s$ length of telson falling short of distal tip of the peduncle), telson apex with 2 stout setae on each side (vs 3-4 stout setae).

The following characters can be used to distinguish Gammarus pontual sp. nov. from G. hongyuanensis (characters for the later species within round brackets): small eyes (Fig. 2A) (vs large size eyes); antenna 1 (Fig. 2B) accessory flagellum 3-articulate (vs 4-articulate); antenna 2 (Fig. 2C) without calceoli (vs calceoli present); coxae 1-4 (Figs. 4A, 5A and 6A, B) with no more than 3 setae (vs usually with 3-6 setae); gnathopod 1 (Fig. 4A, B) propodus lateral margin devoid of facial stout setae and palm weakly armed ( $v s$ facial stout setae formula 4-1-2 and palm strongly armed); gnathopod 2 (Fig. 5A, B) mesial margin with 3 stout setae (vs 2 stout setae on margin); pereopod 6 (Fig. 6D) basis rather straight (vs basis weakly sinuate); epimeral plate 1 (Fig. 7A) posterior margin glabrous (vs with 4 setules on posterior margin); epimeral plate 2 (Fig. 7B) posteroventral spine moderately projected (vs weakly projected); urosomites 1-3 (Fig. 1B-D) dorsal stout setae formula: 2-2-2, 1-2-1, and 2-0-2 (vs formula: 2-2-2, 2-2-2, and 2-0-2, respectively); telson (Fig. 7G) length exceeding the peduncle of uropod 3 ( $v s$ length of telson falling short of distal tip of the peduncle).

Gammarus pontual sp. nov. and G. frigidus can be separated from each other in that the former species (characters for the latter species within round brackets) possess smaller eyes (Fig. 2A) (vs medium size eyes); the antenna 2 (Fig. 2C) gland cone almost reaching to the apex of the third peduncular article (vs gland cone distinctly reaching to the apex), no calceoli in the flagellum (vs calceoli present); 6 short stout and 2 slender setae in the right maxilla 1 palp (Fig. 3B) (vs palp with 5 stout and 1 slender setae); the inner plate of maxilla 2 (Fig. 3C) with facial oblique row of 53 slender setae ( $v s$ row of only 32 plumose setae); the coxa 4 (Fig. 6B) about 1.2 times longer than wide ( $v s$ coxa 4 as long as wide); the posterior margin of the gnathopod 1 (Fig. 4A, B) propodus without stout setae (vs 9 stout setae on propodus); the gnathopod 2 (Fig. 5A, B) carpus distinctly shorter than propodus, being about 0.7 times the length of propodus (vs carpus only slightly shorter than propodus) and acute palm (vs transverse palm); slender and long pereopods 5-7 (Fig. 6C-E) basis (vs robust and short basis); the urosomites 1-3 (Fig. 1B-D) not dorsally elevated and dorsal stout setae formula: 2-2-2, 1-2-1, and 2-0-2 (vs urosomites 1-2 slightly dorsally elevated and formula: 3-2-1-3, $3-2-3$, and 2-0-2, respectively); 1 dorsal stout seta on the uropod 1 (Fig. 7D) outer ramus (vs 3 dorsal stout setae); the telson (Fig. 7G) apex provided with 2 stout setae on each side (vs telson apex with 3-4 stout setae on each side).

Gammarus pontual sp. nov. distinguishes itself from G. jaspidus by having (characters for the later species within round brackets) small eyes (Fig. 2A) (vs medium size eyes); the antenna 2 (Fig. 2C) flagellum without calceoli (vs some articles only with calceoli); the palp of the right maxilla 1 (Fig. 3B) with 6 short stout and 2 slender setae ( $v s$ right maxilla 1 with 5 stout and 2 slender setae); the maxilla 2 (Fig. $3 \mathrm{C}$ ) inner plate with facial oblique row of 53 slender setae (vs 27 plumose setae); the posterior margin of the gnathopods $1-2$ (Figs. $4 \mathrm{~A}, \mathrm{~B}$ and $5 \mathrm{~A}, \mathrm{~B}$ ) propodus without stout setae (vs 10 and 6 stout setae on the gnathopods 1-2 propodus, respectively); the posterior margin of the pereopods 3-4 (Fig. 6A, B) meri with short to medium setae (vs meri with very long setae); the pleonites 1-3 not dorsally elevated and devoid of setae, (vs pleonites 1-3 weakly dorsally elevated and provided with several short setae); the pleopod 2 (Fig. 8B) with 2 retinacula (vs pleopod 2 with 3 retinacula); the urosomites 1-3 (Fig. 1B-D) not dorsally elevated and dorsal stout setae formula: 2-2-2, 1-2-1, and 2-0-2 (vs urosomites 1-2 elevated and dorsal stout setae formula: 3-3-1-3, 2-2-2, and 0-2-0, respectively); and the uropod 1 (Fig. 7D) outer ramus with 1 dorsal stout seta (vs 3 stout setae).

\section{ACKNOWLEDGEMENTS}

L.F.A. is supported by Fundação de Amparo à Ciência e Tecnologia do Estado de Pernambuco (FACEPE), process number BFP-0052-1.08/20. A.R.S. is supported by Programa de Incentivo à Produção Científica, Técnica e Artística (PROCIÊNCIA) and Fundação Carlos Chagas Filho de Amparo à Pesquisa do Estado do Rio de Janeiro (FAPERJ), process number E-26/202.768/2019. M.T. thanks Conselho Nacional de Desenvolvimento Científico e Tecnológico (309488/2020-6) for supporting studies on the systematics of marine and freshwater crustaceans.

\section{AUTHORS' CONTRIBUTIONS}

L.F.A.: Conceptualization, Methodology, Investigation, Formal Analysis, Writing - original draft. M.T. and A.R.S.: Conceptualization, Investigation, Supervision, Writing - review \& editing. All the authors actively participated in the discussion of the results, they reviewed and approved the final version of the paper. Authors declare there are no conflicts of interest. 


\section{REFERENCES}

Garm, A. \& Watling, L. 2013. The crustacean integument: setae, setules, and other ornamentation. In:Watling, L. \& Thiel, M. (Eds.). The natural history of the crustacea. functional morphology and diversity. Oxford, Oxford University Press. p. 167-198.

Horton, T.; Lowry, J.; De Broyer, C.; Bellan-Santini, D.; Coleman, C.0.; Corbari, L.; Costello, M.J.; Daneliya, M.; Dauvin, J.-C.; Fišer, C.; Gasca, R.; Grabowski, M.; Guerra-García, J.M.; Hendrycks, E.; Hughes, L.; Jaume, D.; Jazdzewski, K.; Kim, Y.-H.; King, R.; Krapp-Schickel, T.; LeCroy, S.; Lörz, A.-N.; Mamos, T.; Senna, A.R.; Serejo, C.; Sket, B.; Souza-Filho, J.F.; Tandberg, A.H.; Thomas, J.D.; Thurston, M.; Vader, W.; Väinölä, R.; Vonk, R.; White, K.; Zeidler, W. 2021. World Amphipoda Database. Gammarus Fabricius, 1775. Available: http://www.marinespecies.org/aphia. php?p=taxdetails\&id=101537. Access: 09/03/2021.
Hou, Z. \& Li, S. 2018. Four new Gammarus species from Tibetan Plateau with a key to Tibetan freshwater gammarids (Crustacea, Amphipoda, Gammaridae). ZooKeys, 747: 1-40. D0I

Hou, Z. \& Sket, B. 2015. A review of Gammaridae (Crustacea: Amphipoda): the family extent, its evolutionary history, and taxonomic redefinition of genera. Zoological Journal of the Linnean Society, 176(2): 323-348. D01

Poore, A.G.B.\& Lowry J.K. 1997. New ampithoid amphipods from Port Jackson, New South Wales, Australia (Crustacea: Amphipoda: Ampithoidae). Invertebrate Taxonomy, 11(6): 897-941.

Väinölä, R.; Witt, J.D.S.; Grabowski, M.; Bradbury, J.H.; Jazdzewski, K. \& Sket, B. 2008. Global diversity of amphipods (Amphipoda; Crustacea) in freshwater. Hydrobiologia, 595: 241-255.

Zamanpoore, M.; Grabowski, M.; Poeckl, M. \& Schiemer F. 2011. Taxonomic review of freshwater Gammarus (Crustacea: Amphipoda) from Iran. Zootaxa, 3140: 1-14. 